\title{
Interactive comment on "Deciphering the Chemical Forms of Gaseous Oxidized Mercury in Florida, USA" by Jiaoyan Huang et al.
}

\section{Anonymous Referee \#2}

Received and published: 8 November 2016

The authors present their latest findings regarding identification of potential different chemical forms of gaseous oxidized mercury (GOM) at a site in Florida. The information presented should be useful to those working in this field. Following are specific comments on the manuscript:

1. Recommend revising the title of the manuscript to: "Deciphering some potential chemical forms of gaseous oxidized mercury in Florida, USA"

2. For the unknown compound, recommend discussing in more detail potential candidates.

3. The abstract does not align with the Conclusions section in discussing the five potential different GOM compounds. For instance, the abstract does not mention $\mathrm{HgCl} 2$, and the Conclusions section mentions 2 unknown compounds while the abstract mentions 
one unknown compound.

4. The Introduction, first paragraph, stated that deposition did not decrease with emisACPD sion reductions as coal combustion facilities in the region (please clarify what region?) have implemented control technologies (Prestbo and Gay, 2009). The Prestbo and Gay is an older reference; would this still be the case in $2016 ?$

5. In Section 3.2 Potential GOM Compounds, the end of the third paragraph ("it is interesting to note that the $11 / 19$ profile was similar to $\mathrm{HgCl} 2 "$ ) does not align with the end of the second paragraph which describes $\mathrm{HgBr} 2$ instead of $\mathrm{HgCl} 2$.

Interactive comment on Atmos. Chem. Phys. Discuss., doi:10.5194/acp-2016-725, 2016. 